\section{Buying Time with COVID-19 Outbreak Response, Israel}

\author{
Eyal Leshem, ${ }^{1}$ Arnon Afek, ${ }^{1}$ Yitshak Kreiss \\ Author affiliations: Sheba Medical Center, Israel Ministry of Health, \\ Tel Hashomer, Israel; Sackler School of Medicine, Tel Aviv \\ University, Tel Aviv, Israel
}

DOI: https://doi.org/10.3201/eid2609.201476

Israel's response during the containment phase of the COVID-19 outbreak in early 2020 led to a delay in sustained community transmission and effective mitigation. During February-April 2020, a total of 15,981 confirmed cases resulted in 223 deaths. A total of 179,003 persons reported electronically to selfquarantine and were entitled to paid sick leave.

C ountries' responses to the coronavirus disease (COVID-19) emergency have been determined by their geopolitical, societal, and healthcare system characteristics. A successful response results from early identification of effective interventions tailored for these specific characteristics. At the outset of the COVID-19 outbreak response, Israel's healthcare system faced a chronic shortage of healthcare resources; however, as Israel shifted from containment to mitigation, structural characteristics were leveraged to enhance the response. We describe Israel's healthcare system attributes as related to geopolitical and societal status and how these factors affected the outbreak response.

Israel's national healthcare system serves a population of 9.1 million (1). With 1.8 acute care hospital beds per 1,000 inhabitants and a national total of 758 licensed intensive care unit (ICU) beds, the healthcare system in Israel constantly lacks resources $(2,3)$. In 2016, the average annual occupancy of internal medicine beds was 99\% (monthly range 93\%-107\%) (4); during peak influenza season, overflow patients must receive mechanical ventilation in internal medicine wards. A shortage of surge ICU capacity during the early stages of the COVID-19 outbreak forced Israel to focus on early aggressive containment strategy.

Israel's life expectancy at birth of 82 years ranks eighth among Organization for Economic Cooperation and Development countries $(1,5)$. Israel's National Health Insurance Law (NHIL) guarantees that every legal resident receives all ambulatory and urgent medical care with very low copayment. Robust

${ }^{1}$ These authors contributed equally to this article. community-based healthcare services reduce the need for emergency visits to acute care medical centers. When medically indicated, all urgent care referrals and hospitalizations are free of charge. The result of these policies was that patients with suspected COVID-19 were assessed, isolated, and treated without individual hesitancy or fear of medical expenses.

During a state of national emergency, the Ministry of Health $(\mathrm{MoH})$ assumes control of hospital referrals and admissions, specifically ICU hospitalizations. Stockpiles of pandemic preparedness emergency equipment, including mechanical ventilators, personal protection equipment, and critical medication, are inventoried and managed at the national level. Throughout peak COVID-19 transmission, the $\mathrm{MoH}$ coordinated and diverted admissions of mechanically ventilated patients to avoid overwhelming ICU capacity.

Israel's land borders are infrequently traversed by international travels, and the country is functionally a geopolitical island. In 2019, of 4.6 million tourist entries into Israel, $88 \%$ were via international flights (6). Despite its culturally and politically diverse population, Israel's society shows social cohesion, resilience, and trust in public health and government institutions.

When the COVID-19 epidemic was first reported, Israel's $\mathrm{MoH}$ implemented a containment strategy that consisted of early travel restrictions to countries reporting COVID-19 transmission, as well as extensive testing and self-reported quarantine of returned travelers (Appendix Figures 1-3, https:/ / wwwnc.cdc.gov/EID/article/26/9/20-1476-App1. pdf) (7). Patient contacts were identified through contact tracing and mobile phone surveillance. The $\mathrm{MoH}$ posted the whereabouts of confirmed cases on its website and through a mobile phone application. Persons could ascertain and report patient exposure electronically to the $\mathrm{MoH}$ and enter selfquarantine at home. Quarantined persons reporting electronically were issued a general statement of illness and became entitled to paid sick leave for the duration of quarantine time, enforced on employers by emergency $\mathrm{MoH}$ regulations and upheld by the Israel supreme court (8). Overall, by April 30, 2020, a total of 179,003 persons had self-reported to quarantine; 89,775 (50\%) were returned travelers, and $89,228(50 \%)$ were identified contacts of confirmed cases (9; Appendix Figure 4). To address increased transmission in ultra-Orthodox neighborhoods and in several Arab districts, focal lockdown measures were implemented in late April 2020. Cultural 
characteristics and communal responsibility led to public adherence to these sometimes onerous requirements and contributed to civil obedience.

Altogether, Israel's containment measures proved successful in creating weeks of delay in peak transmission, more than those for some countries in Europe and cities in the United States (Figure). This delay afforded Israel's healthcare system and the $\mathrm{MoH}$ time to implement preparedness measures including medical staff training, emergency department preparation for suspected patient isolation, building isolated COVID-19 units, and shifting resources to compensate for the low number of ICU beds. For example, by April 9, Sheba Medical Center in Tel Hashomer had built 327 isolated COVID-19 ICU hospitalization beds with mechanical ventilation capacity, completely separated from its 71 general (non-COVID-19) ICU beds (10).
Moving from containment to mitigation, widescale social distancing measures were implemented (Appendix Table). These measures included school closure, movement and travel restrictions, discontinuation of nonessential work and commerce, and complete national curfew during the holidays of Passover and Independence Day. Local curfews were instituted in neighborhoods and cities with high COVID-19 incidence and in Muslim populations during Ramadan.

Taken together, these containment and mitigation steps may have contributed to the relatively low peak incidence, low mortality rate, and preservation of healthcare system function in Israel (Figure; Appendix Table). On the basis of these experiences to date, we recommend that countries fully leverage their particular geopolitical, social, and healthcare system characteristics as soon as possible in response to crises of such magnitude.

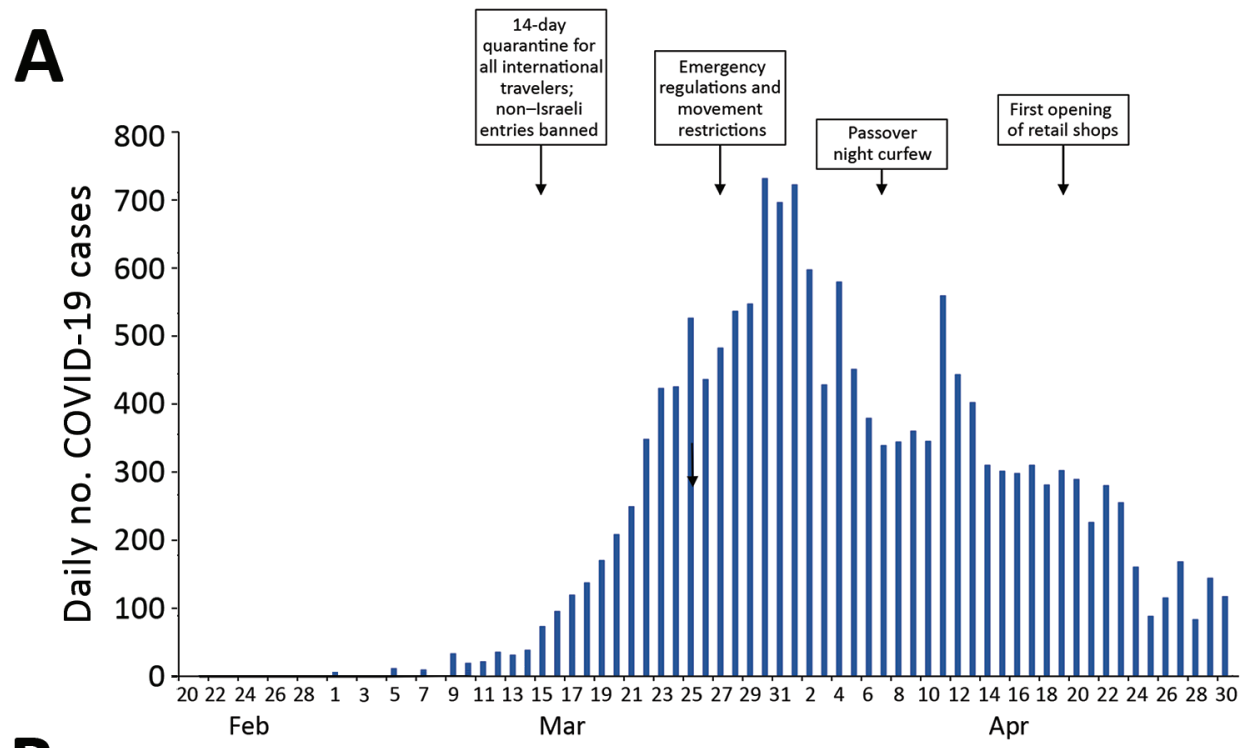

Figure. Numbers of COVID-19 cases and key public health interventions by date of implementation, Israel, February-April, 2020: A) daily numbers; B) cumulative totals.

B

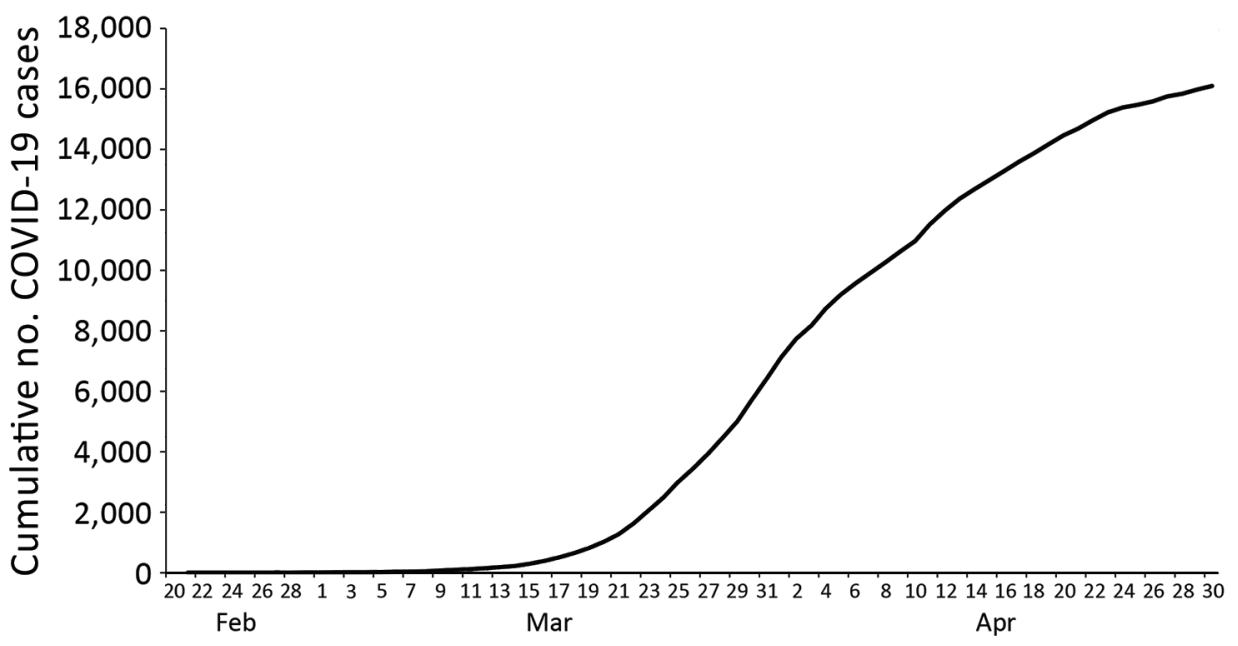




\begin{abstract}
About the Author
Dr. Leshem is a clinical associate professor at Tel Aviv University School of Medicine and the director of the Institute for Travel Medicine and Tropical Diseases at Sheba Medical Center in Tel Hashomer, Israel. His research interests include global health, epidemiology, and vaccine-preventable diseases.
\end{abstract}

\section{References}

1. Israel Central Bureau of Statistics. Population of Israel on the eve of 2020. 2019 [cited 2020 Mar 25]. https:/ / www.cbs.gov. il/en/mediarelease/Pages/2019/Population-of-Israel-onthe-Eve-of-2020.aspx

2. Organization for Economic Cooperation and Development. OECD data: hospital beds. 2020 [cited 2020 Mar 22]. https:/ / data.oecd.org/healtheqt/hospital-beds.htm

3. State of Israel Ministry of Health. Hospitalization beds in Israel, January 2020 [in Hebrew]. 2020 [cited 2020 Apr 12]. https://www.health.gov.il/UnitsOffice/HD/MTI/info/ Pages/licensed_inpatient_hospital_beds.aspx

4. State of Israel Ministry of Health Information Division. Hospital occupancy by admission ward and month, 2016-2017 [in Hebrew]. 2017 [cited 2020 Mar 25] https://www.health.gov.il/UnitsOffice/HD/MTI/info/ Pages/hospital_Beds.aspx

5. Chernichovsky D. Not "socialized medicine" - an Israeli view of health care reform. N Engl J Med. 2009;361:e46. https:/ / doi.org/10.1056/NEJMp0908269

6. Israel Central Bureau of Statistics. Israel visitor arrivals in January-November 2019 [in Hebrew]. 2020 [cited 2020 Mar 25]. https://www.cbs.gov.il/he/mediarelease/ DocLib/2019/367/28_19_367b.pdf

7. State of Israel Ministry of Health. HaMagen: the Ministry of Health app for fighting the COVID-19 outbreak. 2020 [cited 2020 May 12]. https:/ / govextra.gov.il/ministry-of-health/ hamagen-app/download-en

8. State of Israel Ministry of Health. A general statement of illness for isolated workers. 2020 [cited 2020 May 12]. https://govextra.gov.il/ministry-of-health/corona/ corona-virus-en

9. State of Israel Ministry of Health . COVID-19 resources [in Hebrew]. 2020 [cited 2020 May 12]. https:/ / data.gov.il/ dataset/covid-19</eref>

10. Leshem E, Klein Y, Haviv Y, Berkenstadt H, Pessach IM. Enhancing intensive care capacity: COVID-19 experience from a tertiary center in Israel. Intensive Care Med. 2020 May 25 [Epub ahead of print]. PubMed https:/ / doi.org/10.1007/ s00134-020-06097-0

Address for correspondence: Eyal Leshem, Institute for Travel Medicine and Tropical Diseases, Sheba Medical Center, Tel Hashomer 52621, Israel; email: Eyal.Leshem@sheba.health.gov.il

\section{Effectiveness of N95 Respirator Decontamination and Reuse against SARS-CoV-2 Virus}

\author{
Robert J. Fischer, Dylan H. Morris, \\ Neeltje van Doremalen, Shanda Sarchette, \\ M. Jeremiah Matson, Trenton Bushmaker, \\ Claude Kwe Yinda, Stephanie N. Seifert, \\ Amandine Gamble, Brandi N. Williamson, \\ Seth D. Judson, Emmie de Wit, James O. Lloyd-Smith, \\ Vincent J. Munster
}

\begin{abstract}
Author affiliations: National Institute of Allergy and Infectious
Diseases, Hamilton, Montana, USA (R.J. Fischer, N. van

Doremalen, S. Sarchette, M.J. Matson, T. Bushmaker,

C.K. Yinda, S.N. Seifert. B.N. Williamson, E. de Wit, V.J. Munster); Princeton University, Princeton, New Jersey, USA (D.H. Morris); Marshall University, Huntington, West Virginia, USA (M.J. Matson); University of California, Los Angeles, Los Angeles, California, USA (A. Gamble, J.O. Lloyd-Smith), University of Washington, Seattle, Washington, USA (S.D. Judson)
\end{abstract}

\section{DOI: https://doi.org/10.3201/eid2609.201524}

The coronavirus pandemic has created worldwide shortages of $\mathrm{N} 95$ respirators. We analyzed 4 decontamination methods for effectiveness in deactivating severe acute respiratory syndrome coronavirus 2 virus and effect on respirator function. Our results indicate that N95 respirators can be decontaminated and reused, but the integrity of respirator fit and seal must be maintained.

T he unprecedented pandemic of coronavirus disease has created worldwide shortages of personal protective equipment, in particular respiratory protection such as N95 respirators (1). Transmission of severe acute respiratory syndrome coronavirus 2 (SARS-CoV-2) occurs frequently in hospital settings; numerous reported cases of nosocomial transmission highlight the vulnerability of healthcare workers (2). The environmental stability of SARS-CoV-2 virus underscores the need for rapid and effective decontamination methods.

In general, N95 respirators are designed for one use before disposal. Extensive literature is available for decontaminating N95 respirators, of either bacterial spores, bacteria, or respiratory viruses (e.g. influenza A virus) (3-6). Effective inactivation methods for these pathogens and surrogates include UV light, ethylene oxide, vaporized hydrogen peroxide (VHP), gamma irradiation, ozone, and dry heat (A. Cramer et al., unpub data, https:// doi.org/10.1101/2020.03.28.2 0043471) (3-6). The filtration efficiency and fit of N95 respirators has been less well explored, but reports 